\title{
Determine the Dentists' Practice in Compliance with General and Guidelines for Handling Coronavirus Disease 2019: A Systematic Review and Meta-analysis
}

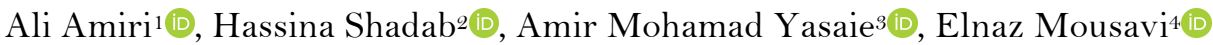

\begin{abstract}
'Department of Orthodontics, College of Stomatology, The First Affiliated Stomatological Hospital, Xi'an Jiaotong University, Xi'an 710004, PR China.

2Department of Periodontics, School of Dentistry, Kabul University of Medical Sciences, Kabul, Afghanistan.

${ }^{3}$ Department of Periodontics, School of Dentistry, Kerman University of Medical Sciences, Kerman, Iran.

${ }^{4}$ Dental Sciences Research Center, Department of Endodontics, School of Dentistry, Guilan University of Medical Sciences, Rasht, Iran.
\end{abstract}

Correspondence: Ali Amiri, Department of Orthodontics, College of Stomatology, The First Affiliated Stomatological Hospital, Xi'an Jiaotong University, Xi’an 710004, PR China. E-mail: draliamiri2020@gmail.com

Academic Editor: Lucianne Cople Maia

Received: 17 February 2021 / Review: 12 June 2021 / Accepted: 04 August 2021

How to cite: Amiri A, Shadab H, Yasaie AM, Mousavi E. Determine the dentists' practice in compliance with general and guidelines for handling coronavirus disease 2019: a systematic review and meta-analysis. Pesqui Bras Odontopediatria Clín Integr. 202 1; $21:$ e0042. https://doi.org/10.1590/pboci.2021.154

\begin{abstract}
Objective: To determine the Dentists' practice in compliance with general and guidelines for handling Coronavirus Disease 2019. Material and Methods: PubMed, Embase, ISI, Scopus, Medicine have been used to search for articles until September 2020. EndNote X9 was used to manage electronic resources as a resource. Joanna Briggs Institute reviewer's manual (JBI) tools was used to assess the quality of studies included in the current systematic and meta-analysis review. The $95 \%$ confidence interval (CI) effect size, the random effect model, and the Restricted maximum-likelihood (REML) methods have all been calculated. I $^{2}$ values of more than $50 \%$ indicated moderate-to-high heterogeneity. Stata/MP v.16 (the fastest version of Stata) statistical software was used to evaluate the Meta-analysis. Results: 39 articles were found in the initial keyword search. The full text of 16 studies was reviewed, and six studies were selected in the end. $72 \%$ of participants used a face mask during the dental procedure $(72 \%, 95 \% \mathrm{CI} ; 40 \%-100 \%)$. $63 \%$ of participants measured fever when patients arrived during the COVID-19 pandemic (63\%, 95\% CI; 46\%$79 \%$ ). Moreover, $72 \%$ of participants used a face mask during the dental procedure $(72 \%, 95 \% \mathrm{CI} ; 40 \%$ $100 \%)$. According to JBI tools, all studies had a moderate risk of bias. Conclusion: The results show that the performance of dental professionals in the conditions of the COVID-19 epidemic is not favorable. Training should be under the standards of treatment guidelines and further measures so that dental professionals can show proper practice by increasing their awareness of this virus and following up on its infection.
\end{abstract}

Keywords: Coronavirus; Dentistry; Practice Patterns, Dentists'. 


\section{Introduction}

In Wuhan, China, in early December 2019, an unknown virus appeared that caused pneumonia [1]. It then became an epidemic, and on 30 January 2020, the WHO reported the outbreak as a public health emergency and an international concern [2]. In addition, the name of this virus was announced Coronavirus (COVID-19).

The rapid spread of this virus and the lack of sufficient information about this virus caused confusion, misinformation, and opinions without much scientific basis, even in the prevailing scientific communities [3]. Studies in different countries provide new information every day. According to the WHO, the global mortality rate over time was estimated at 5.7\% using a 14-day estimate [4]. Early studies reported that the COVID-19 was transmitted from animals to humans, but more recent studies have shown that the COVID-19 can be transmitted from humans to humans through droplets or direct contact $[5,6]$.

So far, the 2019-nCoV has affected more than 43,150,456 reported cases, according to a new report by the Center for Systems Science and Engineering (CSSE) at Johns Hopkins University (JHU) (26 October 2020). As a result, dentists need to evaluate effective strategies to prevent COVID-19 infection. Studies have shown that one of the most at-risk groups in COVID-19 is dentistry. The Centers for Disease Control (CDC), in addition, adhering to standard precautions, sets guidelines temporarily and asks dentists to delay elective procedures, surgeries, or temporary dental visits.

The use of checklists is recommended for all dentists; this checklist includes disinfection protocol, use of personal protective equipment (PPE), and frequent handwashing [2,7-11]. It is emphasized that only patients who have an emergency should be treated [12]. Due to the importance of the subject, the researchers decided to study the performance of dentists in the COVID-19 epidemic with a systematic review and metaanalysis study.

The present study aimed to determine the Dentists' Awareness, Perception, and Attitude regarding COVID-19 in compliance with general and guidelines for handling Coronavirus Disease 2019.

\section{Material and Methods}

PubMed, Embase, ISI, Scopus, Medicine have been used to search for articles until September 2020. Therefore, EndNote X9 is used to manage electronic resources. PubMed Searching was performed using mesh terms:

("COVID-19" [Supplementary Concept] OR "severe acute respiratory syndrome coronavirus 2" [Supplementary Concept]) AND "Dental Health Services"[Mesh]) OR ("Dentists"[Mesh] OR "Infectious Disease Transmission, Professional-to-Patient"[Mesh])) OR "Dental Instruments"[Mesh]. The following keywords were used to search in other databases: COVID-19, Dental Instruments, and Dental Health Services, Dentists' Practice, Compliance, Years into Practice, face mask, body temperature, Cough, Handwashing, Awareness, Perception, and Attitude.

Inclusion criteria included were all types of observational studies, Dental professionals, the outcome of the studies would be the practice of dental professionals to COVID-19. The language of study was not considered important. This systematic review has been carried based on the key consideration of the PRISMA Statement-Preferred Reporting Items for the Systematic Review and Meta-analysis [13].

\section{Data Extraction Methods}

Data extracted from the studies were include, study, sample size, qualification, years into practice. In addition, Joanna Briggs Institute reviewers manual (JBI) tools [14] were used to assess the quality of studies 
included in the current systematic and meta-analysis review. The scale scores for low risk were 7-8 and for moderate and high risk was 4-6 and below four, respectively. The scale range from 0 to 8 , with a higher score indicating higher quality.

Two researchers read the abstracts and full texts and performed data extraction and blind and independently extracted data from the abstract and full text of studies included. Prior to the screening, kappa statistics was carried out to verify the agreement level between the reviewers. The kappa values were higher than 0.80

Effect size REML methods were calculated with a 95\% confidence interval (CI), a random effect model. Random effects were used to deal with potential heterogeneity, and $\mathrm{I}^{2}$ showed heterogeneity. $\mathrm{I}^{2}$ that more than 50\% indicated moderate-to-high heterogeneity. Stata/MP v.16 (the fastest version of Stata) statistical software was used to evaluate the Meta-analysis.

\section{Results}

According to the purpose of the study, there were 39 articles found in the initial keyword search. In the first step of selecting studies34 studies were selected to review the abstracts. Then, studies that did not meet the inclusion criteria were excluded from the study $(n=18)$. The full text of 16 studies was reviewed in the second step (10 studies excluded). Six studies were selected in the end (Figure 1).

\section{Characteristics}

Six studies have been included in the present article. The sample size was 2430 (689 male and 1561 female). Their qualification was dental graduates in 1295 and dental specialists in 1156 participants. Two studies not reported qualifications. Years into practice includes: $<5(\mathrm{n}=339), 5-10(\mathrm{n}=139)$ and $>10(220)$.

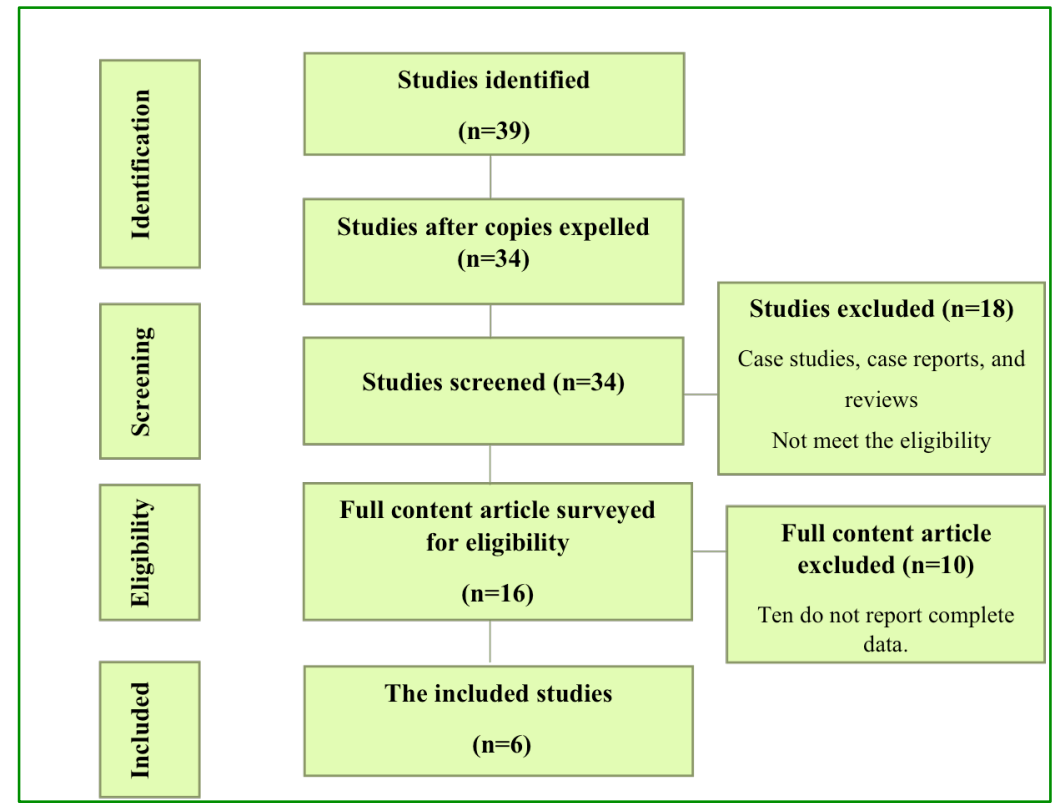

Figure 1. Study attrition.

Bias Assessment

According to Joanna Briggs institute reviewers' manual (JBI) tools, all studies had a total score between 5 to 6 (moderate risk of bias); all included studies were judged as the moderate risk of bias (Table 1). 
Table 1. Studies selected for systematic review and meta-analysis.

\begin{tabular}{|c|c|c|c|c|c|c|c|c|c|c|c|}
\hline \multirow[t]{2}{*}{ Study } & \multirow[t]{2}{*}{ Country } & \multirow[t]{2}{*}{ Data Collected } & \multirow[t]{2}{*}{$\begin{array}{l}\text { Study } \\
\text { Design }\end{array}$} & \multicolumn{2}{|c|}{ Sample Size } & \multicolumn{2}{|c|}{ Qualification } & \multicolumn{3}{|c|}{$\begin{array}{l}\text { Years into } \\
\text { Practice }\end{array}$} & \multirow[t]{2}{*}{ JBI } \\
\hline & & & & Male & Female & BDS & MDS & $<5$ & $5-10$ & $>10$ & \\
\hline $\begin{array}{c}\text { Bansal et al., } \\
2020[2]\end{array}$ & India & $\begin{array}{c}\text { Online Survey } \\
\text { Questionnaires }\end{array}$ & $\begin{array}{c}\text { Cross- } \\
\text { Sectional }\end{array}$ & 129 & 201 & 180 & 150 & 154 & 80 & 96 & 6 \\
\hline $\begin{array}{l}\text { Indu et al., } \\
2020[15]\end{array}$ & Kerala & Questionnaires & $\begin{array}{l}\text { Cross- } \\
\text { Sectional }\end{array}$ & 50 & 82 & 52 & 80 & NR & NR & NR & 6 \\
\hline $\begin{array}{c}\text { Jha et al., } 2020 \\
{[16]}\end{array}$ & Lalitpur & Questionnaires & $\begin{array}{c}\text { Cross- } \\
\text { Sectional }\end{array}$ & 229 & 336 & 150 & 415 & NR & NR & NR & 5 \\
\hline $\begin{array}{c}\text { Sarfaraz et al., } \\
2020[17]\end{array}$ & $\begin{array}{l}23 \text { Different } \\
\text { Countries }\end{array}$ & $\begin{array}{l}\text { Online Survey } \\
\text { Questionnaires }\end{array}$ & $\begin{array}{l}\text { Cross- } \\
\text { Sectional }\end{array}$ & 178 & 207 & NR & NR & & & NR & 5 \\
\hline $\begin{array}{l}\text { Ahmed et al., } \\
2020[18]\end{array}$ & $\begin{array}{l}30 \text { Different } \\
\text { Countries }\end{array}$ & $\begin{array}{l}\text { Online Survey } \\
\text { Questionnaires }\end{array}$ & $\begin{array}{l}\text { Cross- } \\
\text { Sectional }\end{array}$ & 160 & 490 & 913 & 511 & & & NR & 6 \\
\hline $\begin{array}{c}\text { Khader et al., } \\
2020[19]\end{array}$ & Jordan & Questionnaires & $\begin{array}{l}\text { Cross- } \\
\text { Sectional }\end{array}$ & 123 & 245 & NR & NR & 185 & 59 & 124 & 6 \\
\hline
\end{tabular}

Used Face Mask during a Dental Procedure

According to Figure 2, $72 \%$ of participants used a face mask during the dental procedure (72\%, $95 \%$ CI; $40 \%-100 \%)$.

\begin{tabular}{|c|c|c|c|c|}
\hline \multicolumn{3}{|l|}{$\begin{array}{l}\text { face mask } \\
\text { Study }\end{array}$} & $\begin{array}{l}\text { Effect Size } \\
\text { with } 95 \% \mathrm{Cl}\end{array}$ & $\begin{array}{c}\text { Weight } \\
(\%)\end{array}$ \\
\hline Bansal et al.,2020 & & & $0.88[0.76,1.00]$ & 19.79 \\
\hline Indu et al.,2020 & & & $0.84[0.74,0.94]$ & 19.95 \\
\hline Jha et al.,2020 & & & $0.94[0.90,0.98]$ & 20.27 \\
\hline Ahmed et al.,2020 & & & $0.08[0.02,0.14]$ & 20.20 \\
\hline Khader et al.,2020 & & & $0.88[0.76,1.00]$ & 19.79 \\
\hline \multicolumn{5}{|c|}{$-0.72[0.40,1.04]$} \\
\hline \multicolumn{5}{|c|}{ Heterogeneity: $\mathrm{T}^{2}=0.13, \mathrm{I}^{2}=98.94 \%, \mathrm{H}^{2}=94.47$} \\
\hline \multicolumn{5}{|c|}{ Test of $\theta_{1}=\theta_{j}: Q(4)=595.96, p=0.00$} \\
\hline \multicolumn{5}{|l|}{ Test of $\theta=0: z=4.43, p=0.00$} \\
\hline & 0 & .5 & 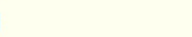 & \\
\hline Random-effects REML model & & & & \\
\hline
\end{tabular}

Figure 2. The Forest plot showed a used face mask during the dental procedure.

Handshaking

According to Figure 3, 80\% of participants avoided handshaking with the patient or colleagues during the COVID-19 pandemic (80\%, 95\% CI; 63\%-97\%).

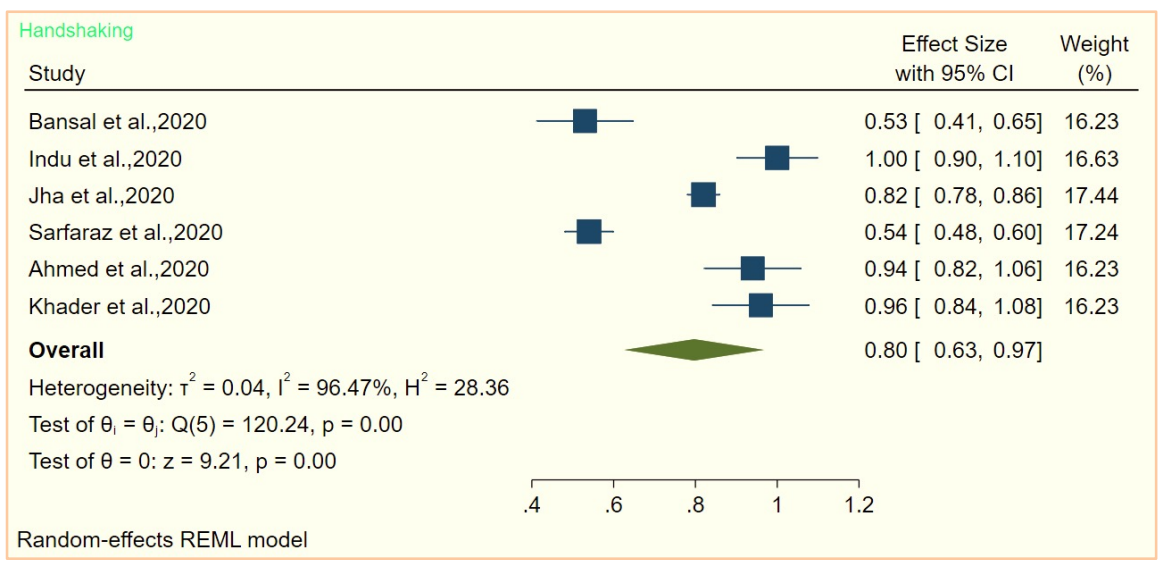

Figure 3. The Forest plot showed avoided handshaking. 
Patient's Body Temperature

According to Figure 4, 63\% of participants measured fever when patients arrived during the COVID19 pandemic $(63 \%, 95 \% \mathrm{CI} ; 46 \%-79 \%)$.

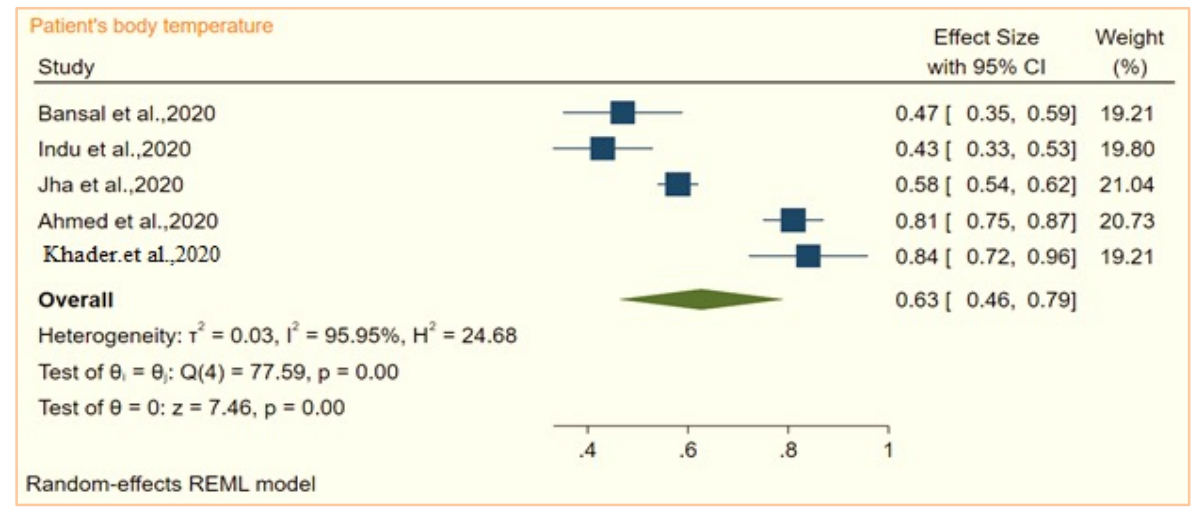

Figure 4. The Forest plot showed the patient's body temperature.

Cough

According to Figure 5, 67\% of participants deferred patients had a cough during the COVID-19 pandemic (67\%, 95\% CI; 34\%-100\%).

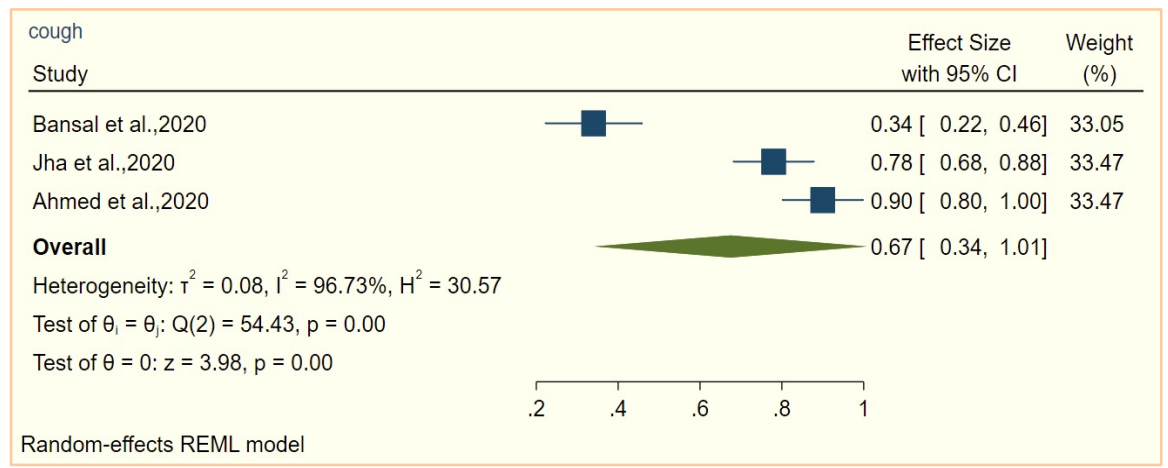

Figure 5. The Forest plot showed that deferred patients had a cough.

Hand Washing

According to Figure 6, 91\% of participants washed their hands after each procedure during the COVID-19 pandemic (91\%, 95\% CI; 79\%-100\%).

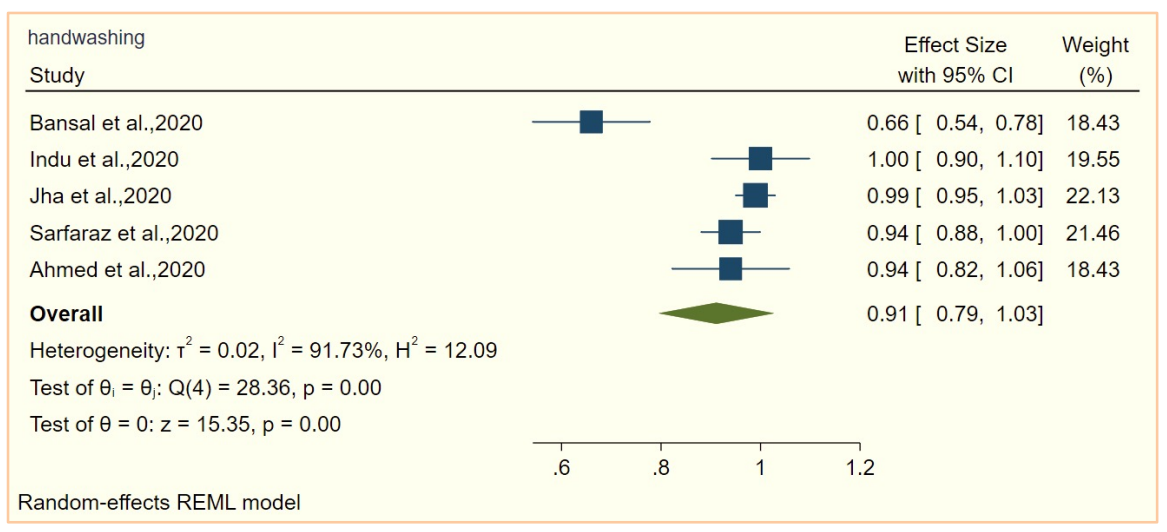

Figure 6. The Forest plot showed handwashing. 
Funnel plots showed the effect size of each variable under consideration; these results indicate that high heterogeneity is observed between studies (Figure 7).

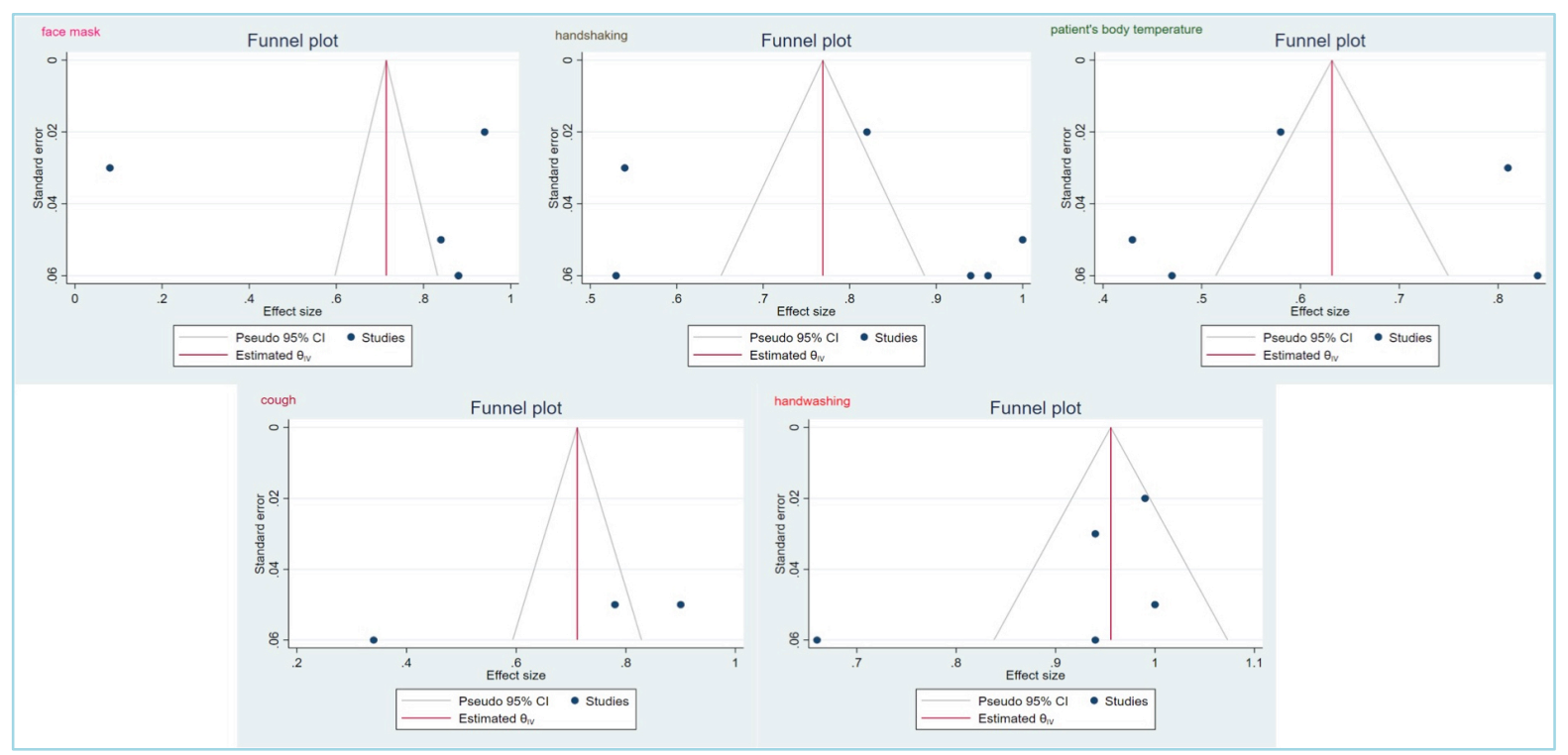

Figure 7. Funnel plots showed the effect size of each variable under consideration.

\section{Discussion}

This systematic review and meta-analysis aimed to determine the dentists' practice in compliance with general and guidelines for handling Coronavirus Disease 2019. The current meta-analysis showed that the most common protocol followed by dentists was hand washing (91\%). Moreover, $80 \%$ of them avoid handshaking. $72 \%$ of the dental professionals wore facemasks. The measurement of patients' body temperature and treatment of patients with cough were $63 \%$ and $67 \%$, respectively, among dental professionals. A previous systematic review and meta-analysis [7] showed that hand washing, worn facemask was $62.82 \%$ and $50.86 \%$, respectively. This discrepancy may be because protocols are now more stringent than before.

As the number of people with COVID-19 increases, so will access to dental services. Studies have shown that $80 \%$ of dentists provide emergency services only, and $17 \%$ of dentists do not provide any services [20]. On the other hand, the restrictions are economically a significant loss for the dental department, affecting the quality of patient care [21]. The Prevention (CDC) and Centers for Disease Control and the American Dental Association (ADA) have called on all dentists to treat only patients in urgent need of care. End of the epidemic Dentists provides other patients with the necessary oral hygiene training, which can be done through the media and cyberspace [7,22-24].

High heterogeneity was observed between the studies, which may not provide strong evidence for the results of the present study. Questionnaires have also been provided to participants in most online studies; this can vary the results of the study. As a result, high heterogeneity between studies must be addressed to provide sufficient evidence. Therefore, it is recommended that more studies be done in this field and the working method and questionnaire be equated with other studies.

The present study used Joanna Briggs Institute reviewers' manual (JBI) tools and according to this tool, all studies had a moderate risk of bias or moderate quality. Further studies of higher quality are needed.

Following the results of the present study, further training should be provided to the dental professional on the following: used personal protective equipment, hand cleanliness practices, personal 
protective equipment (PPE), avoid handshaking. According to the present review, most dental professionals did not perform well practice about COVID-19 prevention protocols. Dentists need to consider each patient as a carrier and take all patient precautions. Adequate training should be given to dentists and all persons involved in dental care. Also, by educating people in the community and avoiding unnecessary visits to dental offices, preventing further transmission of this virus and its spread is possible.

One of the limitations of the present study was that the studies were descriptive, but the sample size was very small, a high heterogeneity was observed between the study methods. They can affect the results of the present study. Therefore, it is suggested that RCT studies and descriptive studies with high sample size and follow-up period be considered.

\section{Conclusion}

The results show that the performance of dental professionals in the conditions of the COVID-19 epidemic is not favorable. Training should be following the standards of treatment guidelines and further measures so that dental professionals can show proper practice by increasing their awareness of this virus and following up on its infection. One of the reasons dentists are most at risk is because they deal with saliva and droplets, which are the main source of COVID-19. Therefore, protocols should be adjusted to reduce the contamination of droplets and aerosols. The results of this study can be used in other epidemics that are similar to the Covid-19 epidemic, and the results of this study can also be used to prevent other viruses.

\section{Authors' Contributions}

\begin{tabular}{|c|c|c|}
\hline & (i) https://orcid.org/0000-0001-9416-808X & $\begin{array}{l}\text { Conceptualization, Methodology, Formal Analysis, Investigation, Writing - Original Draft, } \\
\text { Writing - Review and Editing and Visualization. }\end{array}$ \\
\hline HS & (iD) https://orcid.org/0000-0003-3300-8239 & Methodology, Writing - Original Draft and Writing - Review and Editing. \\
\hline AMY & (iD) https://orcid.org/0000-0003-4957-5692 & Writing - Review and Editing. \\
\hline EM & (iD) https://orcid.org/0000-0001-9442-5509 & Validation and Writing - Review and Editing. \\
\hline
\end{tabular}

\section{Financial Support}

None.

\section{Conflict of Interest}

The authors declare no conflicts of interest.

\section{Data Availability}

The data used to support the findings of this study can be made available upon request to the corresponding author.

\section{References}

[1] Wei FF, Moradkhani A, Hemmati Hezaveh H, Miraboutalebi SA, Salehi L. Evaluating the treatment with favipiravir in patients infected by COVID-19: a systematic review and meta-analysis. IJSRDMS 2020; 2(3):87-91. https://doi.org/10.30485/IJSRDMS.2020.241494.1079

[2] Bansal P, Agnihotri A, Gupta A, Singh G, Kaur A, Arora R, et al. Emergency preparedness of oral health professionals during COVID-19 pandemic: A knowledge, attitude, and practices study. Indian J Dent Sci 2020; 12(3):137. https://doi.org/10.4103/IJDS.IJDS_88_20

[3] Casaroto AR, Jamali J, Amini F, Talebzade Toranji M, Kayasöken G. Evaluating epidemiology, symptoms, and routes of COVID-19 for dental care: a literature review. IJSRDMS 2020; 2(2):37-41. https://doi.org/10.30485/IJSRDMS.2020.231680.1056

[4] Gaye B, Fanidi A, Jouven X. Denominator matters in estimating COVID-19 mortality rates. Eur Heart J 2020; 41(37):3500. https://doi.org/10.1093/eurheartj/ehaa282 
[5] Baghizadeh Fini M. Transmission routes of SARS-CoV-2 in dentistry: a literature review. IJSRDMS 2020; 2(4):1357. https://doi.org/10.30485/ijsrdms.2020.252402.1088

[6] Borges do Nascimento IJ, Cacic N, Abdulazeem HM, von Groote TC, Jayarajah U, Weerasekara I, et al. Novel coronavirus infection (COVID-19) in humans: a scoping review and meta-analysis. J Clin Med 2020; 9(4):941. https://doi.org/10.3390/jcm9040941

[7] Tefera AT, Asefaw K, Bekele B, Ayelign A, Aragie H, Ayhualem S, et al. Dental professionals knowledge, attitude, and practice towards to COVID-19: systematic review and meta-analysis. Preprints 2020; 2020090439. https://doi.org/10.20944/preprints202009.0439.v1

[8] Zeenny RM, Ramia E, Akiki Y, Hallit S, Salameh P. Assessing knowledge, attitude, practice, and preparedness of hospital pharmacists in Lebanon towards COVID-19 pandemic: a cross-sectional study. J Pharm Policy Pract 2020; 13(1):1-2. https://doi.org/10.1186/s40545-020-00266-8

[9] Olum R, Kajjimu J, Kanyike AM, Chekwech G, Wekha G, Nassozi DR, et al. Perspective of medical students on the COVID-19 pandemic: survey of nine medical schools in Uganda. JMIR Public Health Surveill 2020; 6(2):e19847. https://doi.org/10.2196/19847

[10] Ferdous MZ, Islam MS, Sikder MT, Mosaddek AS, Zegarra-Valdivia JA, Gozal D. Knowledge, attitude, and practice regarding COVID-19 outbreak in Bangladesh: An online-based cross-sectional study. PloS One 2020; 15(10):e0239254. https://doi.org/10.1371/journal.pone.0239254

[11] Salman M, Mustafa Z, Asif N, Zaidi HA, Shehzadi N, Khan TM, et al. Knowledge, attitude and preventive practices related to COVID-19 among health professionals of Punjab province of Pakistan. J Infect Dev Ctrie 2020; 14(07):70712. https://doi.org/10.3855/jidc. 12878

[12] Hundekari J, Mittal R, Hundekari J, Mittal R, Wasnik S, Kot L. Perception of equivalence between online and face-toface academic activities by undergraduate medical students during COVID-19 Pandemic. IJSRDMS 2020; 2(4):11520. https://doi.org/10.30485/IJSRDMS.2020.253310.1091

[13] Moher D, Liberati A, Tetzlaff J, Altman DG, Altman D, Antes G, et al. Preferred reporting items for systematic reviews and meta-analyses: The PRISMA statement (Chinese edition). Chin J Integr Med 2009; 7(9):889-96. https://doi.org/10.3736/jcim20090918

[14] Peters M, Godfrey C, McInerney P, Soares C, Khalil H, Parker D. The Joanna Briggs Institute Reviewers' Manual 2015: Methodology for JBI Scoping Reviews. The Joanna Briggs Institute, 2015.

[15] Indu M, Syriac G, Beena VT, MCherian L, Paul S, Sathyan P. Assessment of knowledge, attitude and practice regarding dental care during COVID 19 pandemic-a cross sectional study among dental health professionals in tertiary care centers of Kerala. IOSR-JDMS 2020; 19(5):5-10. https://doi.org/10.9790/0853-1905110510

[16] Jha N, Singh N, Bajracharya O, Manandhar T, Devkota P, Kafle S, et al. Knowledge about the COVID-19 pandemic among undergraduate medical and dental students in Lalitpur, Nepal. Med Pharm Rep 2020; 1-9. https://doi.org/10.21203/rs.3.rs-41172/v2

[17] Sarfaraz S, Shabbir J, Mudasser MA, Khurshid Z, Al-Quraini AA, Abbasi MS, et al. Knowledge and attitude of dental practitioners related to disinfection during the COVID-19 pandemic. Healthcare 2020; 8(3):232. https://doi.org/10.3390/healthcare8030232

[18] Ahmed MA, Jouhar R, Ahmed N, Adnan S, Aftab M, Zafar MS, et al. Fear and practice modifications among dentists to combat Novel Coronavirus Disease (COVID-19) outbreak. Int J Environ Res Public Health 2020; 17(8):2821. https://doi.org/10.3390/ijerph 17082821

[19] Khader Y, Al Nsour M, Al-Batayneh OB, Saadeh R, Bashier H, Alfaqih M, et al. Dentists' awareness, perception, and attitude regarding COVID-19 and infection control: cross-sectional study among Jordanian dentists. JMIR Public Health Surveill 2020; 6(2):e18798. https://doi.org/10.2196/18798

[20] American Dental Association. COVID-19 Impact on Dental Practices. 2020. Available from: https://www.ada.org/en/scienceresearch/health-policy-institute/covid-19-dentists-economic-impact. [Accessed on January 14, 2021].

[21] Nasseh K, Vujicic M. Modeling the impact of COVID-19 on US dental spending. Health Policy Institute Research Brief. American Dental Association, 2020.

[22] Keyhan SO, Fallahi HR, Motamedi A, Khoshkam V, Mehryar P, Moghaddas O, et al. Reopening of dental clinics during SARS-CoV-2 pandemic: an evidence-based review of literature for clinical interventions. Maxillofac Plast Reconstr Surg 2020; 42(1):1-3. https://doi.org/10.1186/s40902-020-00268-1

[23] Aponte Mendez M, Rivera Marval EK, Talebzade Toranji M, Amini F, Casaroto AR. Dental care for patients during the Covid-19 outbreak: a literature review. IJSRDMS 2020; 2(2):42-5. https://doi.org/10.30485/IJSRDMS.2020.232096.1058

[24] Xavier TB, Barbosa GM, da Silva BB, Daroz BG, dos Santos YP, Neto NC, et al. Dental treatment protocol in bucomaxillofacial surgery in the context of COVID-19. Braz J Health Rev 2020; 3(3):4484-500. https://doi.org/10.34119/bjhrv3n3-047 